\title{
SISTEM INFORMASI MANAJEMEN \\ PERPUSTAKAAN POLITEKNIK NEGERI KETAPANG BERBASIS KONSEP GROUP TECHNOLOGY
}

\author{
Epriyandi ${ }^{1}$ \\ ${ }^{1}$ Departemen Teknik Mesin, Politeknik Negeri Ketapang \\ Jl. Rangga Sentap-Dalong, Sukaharja, Ketapang, Kalimantan Barat \\ Email : epriyandi@gmail.com
}

\begin{abstract}
Abstrak. Politeknik Negeri Ketapang merupakan salah satu perguruan tinggi yang berada di Kabupaten Ketapang Provinsi Kalimantan Barat. Politeknik Negeri Ketapang memiliki suatu perpustakaan, dimana terdapat berbagai macam jenis buku yang sering digunakan oleh sivitas akademika maupun pihak luar. Data- data tentang aset yang meliputi buku sangatlah kompleks, dimana dalam mengelola data-data tersebut, perpustakaan Politeknik Negeri Ketapang masih menggunakan dokumen kertas yang disimpan dalam filling cabinet, sehingga terdapat kendala dalam penyediaan informasi atau laporan-laporan yang mendukung dalam pengambilan keputusan serta pengecekan persediaan buku dalam upaya peningkatan pelayanan kepada pembaca. Pada penelitian ini, dilakukan perancangan Sistem Informasi Perpustakaan Politeknik Negeri Ketapang berbasis Konsep Group Technology, dimana dalam implementasinya menggunakan Software Microsoft Access 2007. Penelitian dilakukan melalui beberapa tahapan, antara lain tahap perencanaan, analisis, perancangan, implementasi. Pada bagian akhir, dilakukan tahap pengujian. Hasil pengujian menunjukkan bahwa sistem informasi telah berjalan dengan baik dan sesuai dengan desain yang telah dibuat sebelumnya. Hal tersebut dapat dilihat dengan laporan-laporan yang dihasilkan yang dapat mendukung dalam pengambilan keputusan, dan aplikasi sistem informasi lebih baik dibanding dengan sistem yang telah berlaku. Hal tersebut salah satunya dapat dilihat dari segi efisiensi waktu dalam hal pencarian data serta pembuatan laporan.
\end{abstract}

\section{Keywords: Sistem Informasi, Perpustakaan, Group Technology}

Abstract. Politechnic Ketapang is one of the institutionals that's located in Ketapang regency, West Borneo Province. Many facilities that Politechnic Ketapang provides to support the students in learning. One of the facilities that provide is library. It has various and useful books that are used by lectures and students to complete their reference. Unfortunately, they have difficulties to find the books because it has just kept in some documents and put in filling cabinet. They hard to find the information, stock, and data about the book. Whether the books are are still borrowed or not, and where the books are placed. It also makes a librarian find his hard task to give best service quality for them. With that condition, the writer needs to hold a research to give a solution into a problem in Politechnic Ketapang library. This research has a purpose to design and to build a management information system in arranging and managing the datas that library have, so that the accuracy of information about the books more effective and efficient. Besides that, with management information system can give the solution to make easy and fast in knowing a data, efficiently in keeping the books, and of course safe. This research is designed to use a management information system of Politechnic Ketapang library with have a base "group technology" and used "microsoft access 2007 software". This research is done through some steps such as planning, analysis, design, implementation. In the last step is a test step, that involves verification, validation, and prototype test.

Keywords : Information System, Library, Group Technology

\section{Pendahuluan}

Perpustakaan Politeknik Negeri Ketapang merupakan salah satu dari beberapa unit kerja yang ada di Politeknik Negeri Ketapang. Di dalam Perpustakaan ini, terdapat ribuan buku yang sering digunakan oleh pengunjung perpustakaan. Perlunya peningkatan dan pengembangan dalam pengelolaan unit ini harus dilakukan demi kemajuan unit kerja itu sendiri yang berdampak pada institusi yang menaunginya. Pemanfaatan Teknologi Informasi dalam pengelolaan unit kerja ini sangat diperlukan 
agar pengelolaan terhadap unit ini lebih efektif dan efisien.

Salah satu bidang yang perlu ditangani lebih seksama adalah masalah manajemen data inventaris buku yang ada di perpustakaan. Perpustakaan bukanlah sebuah gedung atau bangunan fisik belaka, akan tetapi perpustakaan adalah tempat dimana komunitas pegawainya memberikan pelayanan kepada pengunjung yang ingin membaca maupun meminjam buku yang ada di perpustakaan. Oleh karena itu, bidang manajemen data inventaris buku merupakan jiwa bagi perpustakaan yang mesti senantiasa mendapatkan perhatian. Pengelolaan data buku bisa menjadi permasalahan yang sangat kompleks apabila hanya ditangani secara konvensional. Pengelolaan data tersebut akan menjadi lebih efektif dan efisien setelah dibantu dengan penggunaan teknologi informasi, yaitu dengan menggunakan Sistem Informasi Manajemen Perpustakaan. Sistem informasi manajemen pada perpustakaan Politeknik Negeri Ketapang ini masih menggunakan cara manual atau konvensional dalam sistem pengolahan data-datanya.

Berdasarkan latar belakang di atas, maka perlu dilakukan penelitian lebih lanjut terhadap Sistem Informasi Manajemen di Perpustakaan Politeknik Negeri Ketapang ini terkait dengan konsep Group Technology.

\section{Landasan Teori}

\subsection{Sistem Database}

Database merupakan kumpulan file-file yang berhubungan secara logis dan digunakan secara rutin pada operasi-operasi sistem informasi manajemen. Semua database umumnya berisi elemen-elemen data yang disusun ke dalam file-file yang diorganisasikan berdasarkan sebuah skema atau struktur tertentu, tersimpan di hardware komputer dan dengan software untuk melakukan manipulasi data untuk kegunaan tertentu. Jadi, suatu database adalah menunjukkan suatu kumpulan tabel yang dipakai dalam suatu lingkup organisasi atau instansi untuk tujuan tertentu.

Sistem basis data/database adalah sistem yang terdiri atas kumpulan file (tabel) yang saling berhubungan dan sekumpulan program (sistem operasi dan DBMS) yang memungkinkan user/pemakai mengelola, mengakses, dan memanipulasi file-file (tabel-tabel) tersebut. Pengertian lain sistem Basis Data adalah suatu sistem menyusun dan mengelola record-record menggunakan computer untuk menyimpan atau merekam serta memelihara data operasional lengkap sebuah organisasi/organisasi, sehingga mampu menyediakan informasi yang optimal yang diperlukan pemakai untuk proses mengambil keputusan.

\subsubsection{Komponen Sistem Database}

Komponen Sistem Database meliputi:

1. Data

Data adalah representasi fakta dunia nyata yang mewakili suatu obyek (spt, manusia: dosen, mhs, pelanggan,dll; barang: buku, meja; peristiwa, konsep, dsb.), yang direkam baik dalam bentuk angka, huruf, teks, gambar atau suara. Dalam sistem database, data harus bersifat:

a. Dipakai bersama

Masing-masing bagian dari database dapat diakses oleh pemakai lebih dari satu orang dalam waktu yang bersamaan, untuk aplikasi yang berbeda.

b. Terintegrasi / terpadu

Database merupakan kumpulan dari berbagai macam file dari aplikasiaplikasi yang berbeda, yang disusun dengan cara menghilangkan bagian-bagian yang rangkap (redundant).

2. Perangkat keras (Hardware)

Perangkat keras yang dibutuhkan dalam sistem database harus memenuhi spesifikasi yang dibutuhkan untuk menjalankan perangkat lunak, agar perangkat lunak sistem database bisa berjalan dengan baik.

3. Perangkat lunak (Software)

Perangkat lunak dalam sistem database berfungsi sebagai perantara (interface) antara pemakai dengan data fisik pada database. Software pada sistem database dapat berupa:

a. Database Management System (DBMS), yang menangani akses terhadap database, sehingga pemakai tidak perlu memikirkan proses penyimpanan dan pengelolaan data secara detail.

b. Program-program aplikasi dan prosedurprosedur perangkat lunak yang digunakan dalam sistem database harus menyediakan fasilitas - fasilitas sebagai berikut:

1) Membuat file

2) Menyisipkan data

3) Menampilkan data

4) Menghapus data

5) Kontrol keamanan

6) Kontrol keterpaduan

4. Pemakai (User)

Pemakai database dibagi atas 3 klasifikasi, yaitu:

a. Database Administrator (DBA), yaitu: 
Orang/team yang bertugas mengelola sistem database secara keseluruhan.

b. Programmer, yaitu:

Orang/team yang bertugas membuat program aplikasi yang mengakses database, dengan menggunakan bahasa pemrograman, seperti Clipper, VB, Oracle baik secara bath maupun online untuk berinteraksi dengan komputer.

c. End-user, yaitu:

Orang yang mengakses database melalui terminal, dengan menggunakan querylanguage atau program aplikasi yang dibuatkan oleh programmer.

\subsubsection{Tujuan Sistem Database}

Tujuan utama dari sistem database adalah praktis dan efisien. Secara terperinci, tujuan dari sistem database adalah sebagai berikut:

1. Menyediakan tempat penyimpanan massal untuk data yang relevan.

2. Memudahkan pemakai dalam mengakses data.

3. Memungkinkan respon yang segera atas permintaan data dari pemakai.

4. Melakukan modifikasi terakhir dengan segera pada database.

5. Memungkinkan secara serentak dan bersamaan beberapa pemakaian database yang berarti juga meningkatkan kebebasan data sehingga berguna untuk beberapa program.

6. Memungkinkan perkembangan lebih lanjut dalam sistem database.

7. Meminimasi duplikasi dan redudansi dalam penyimpanan data.

8. Melindungi data dari gangguan kerusakan atau pemakaian oleh orang yang tidak terotorisasi.

\subsection{Sistem Informasi Manajemen}

\subsubsection{Pengertian Sistem Informasi Manajemen}

Sistem Informasi Manajemen adalah sebuah sistem yang terintegrasi antara manusia dan mesin yang mampu memberikan informasi sedemikian rupa untuk menunjang jalannya operasi, jalannya manajemen dan fungsi pengambilan keputusan di dalam sebuah organisasi. Sistem tersebut menggunakan perangkat keras dan lunak (software dan hardware), prosedur manual, model-model untuk analisa, perencanaan dan pengambilan keputusan juga database (Davis, 1984).

Menurut Ferdinand Magaline, Sistem informasi adalah suatu sistem dalam suatu organisasi yang mempertemukan kebutuhan pengolahan transaksi harian yang mendukung fungsi operasi organisasi yang bersifat manajerial dengan kegiatan strategi dari suatu organisasi untuk dapat menyediakan kepada pihak luar tertentu dengan informasi yang diperlukan untuk pengambilan keputusan.

Dengan demikian dapat disimpulkan bahwa Sistem Informasi Manajemen (SIM) adalah sistem informasi yang terpadu antara manusia dan komputer yang berfungsi dalam menunjang industri kemanajemenan dengan tujuan menyediakan informasi baik kepada pihak manajerial untuk analisa, perencanaan, operasional, dan pengendalian, dalam mendukung pengambilan keputusan dalam sebuah organisasi, maupun informasi kepada pihak luar seperti wisatawan.

\subsubsection{Komponen Sistem Informasi Manajemen}

Sistem informasi manajemen terdiri dari komponenkomponen yang terdiri dari komponen input, komponen model, komponen output, komponen teknologi, komponen hardware, komponen software, komponen basis data, dan komponen kontrol. Semua komponen tersebut saling berinteraksi satu dengan yang lain membentuk suatu kesatuan untuk mencapai sasaran.

1. Komponen input

Input mewakili data yang masuk kedalam sistem informasi manajemen. Input disini termasuk metode dan media untuk menangkap data tentang kemanajemenan yang akan dimasukkan, yang dapat berupa dokumen dokumen dasar.

2. Komponen model

Komponen ini terdiri dari kombinasi prosedur, logika, dan model matematik yang akan memanipulasi data input dan data yang tersimpan di basis data dengan cara yang sudah ditentukan untuk menghasilkan keluaran yang diinginkan.

3. Komponen output

Hasil dari sistem informasi manajemen adalah keluaran yang merupakan informasi tentang kemanajemenan yang berkualitas dan dokumentasi yang berguna untuk semua pemakai sistem.

4. Komponen teknologi

Teknologi merupakan "tool box" dalam sistem informasi manajemen, Teknologi digunakan untuk menerima input, menjalankan model, menyimpan dan mengakses data, menghasilkan dan mengirimkan keluaran, dan membantu pengendalian dari sistem secara keseluruhan.

5. Komponen hardware

Hardware berperan penting sebagai suatu media penyimpanan vital bagi sistem 
informasi manajemen. Yang berfungsi sebagai tempat untuk menampung database atau lebih mudah dikatakan sebagai sumber data dan informasi untuk memperlancar dan mempermudah kerja dari sistem informasi manajemen.

6. Komponen software

Software berfungsi sebagai tempat untuk mengolah, menghitung dan memanipulasi data yang diambil dari hardware untuk menciptakan suatu informasi.

7. Komponen database

Basis data (database) merupakan kumpulan data yang saling berkaitan dan berhubungan satu dengan yang lain, tersimpan di perangkat keras komputer dan menggunakan perangkat lunak untuk memanipulasinya. Data perlu disimpan dalam basis data untuk keperluan penyediaan informasi lebih lanjut. Data di dalam basis data perlu diorganisasikan sedemikian rupa supaya informasi yang dihasilkan berkualitas. Organisasi basis data yang baik juga berguna untuk efisiensi kapasitas penyimpanannya. Basis data diakses atau dimanipulasi menggunakan perangkat lunak yang disebut DBMS (Database Management System).

8. Komponen control

Banyak hal yang dapat merusak sistem informasi manajemen, seperti bencana alam, api, temperatur, air, debu, kecurangankecurangan, kegagalan sistem itu sendiri, ketidak efisienan, sabotase dan lain sebagainya. Beberapa pengendalian perlu dirancang dan diterapkan untuk meyakinkan bahwa halhal yang dapat merusak sistem dapat dicegah ataupun bila terlanjur terjadi kesalahankesalahan dapat langsung cepat diatasi.

\subsubsection{Fungsi Sistem Informasi Manajemen}

Di dalam SIM ini terdapat beberapa fungsi yang dibutuhkan oleh pengguna, diantaranya:

1. Pencarian data.

2. Penginformasian data kepada user (dapat berupa report text dalam bentuk tabel atau dalam bentuk grafik).

3. Penyimpanan data.

Dengan adanya SIM ini, sebuah organisasi mengharapkan suatu sistem yang dapat bekerja secara cepat dan akurat sehingga produktivitas kerja lebih meningkat. Yang perlu diingat bahwa jangan sampai keberadaan sistem tersebut justru menimbulkan masalah baru di dalam organisasi.

\section{Alat dan Bahan Penelitian}

\subsection{Alat}

Adapun alat yang digunakan untuk menunjang penelitian ini sebagai berikut:

1. Komputer

2. Software Microsoft Access 2007

3. Kamera

4. Printer

\subsection{Bahan}

Bahan yang digunakan untuk membuat sistem informasi ini berupa:

1. Data Buku Perpustakaan

2. Data Pegawai Perpustakaan

3. Data Peminjaman Buku Perpustakaan

\section{Metode Penelitian}

\subsection{Sistem Database}

Data dan informasi tentang aset perpustakaan yang meliputi aset buku dan pegawai akan disimpan dalam suatu database yang disebut Sistem Informasi Manajemen Perpustakaan (SIMPUS). SIMPUS tersebut dikembangkan dengan bantuan perangkat lunak Microsoft Access 2007. Dengan demikian, akan dipetik keuntungan sebagai berikut:

1. Kemudahan dan kecepatan dalam pengambilan data (speed) Memudahkan dalam menginput, mencari, maupun dalam mengambil data, karena bersifat file elektronik.

2. Efisiensi ruang penyimpanan (space) Mengurangi / menghilangkan redudansi data.

3. Keakuratan (Accuracy)

Pembentukan kode \& relasi antar data berdasar aturan / batasan (constraint) tipe data, domain data, keunikan data, untuk menekan ketidakakuratan saat entry/ penyimpanan data.

4. Ketersediaan (Avaibility)

Pemilahan data yang sifatnya pasif dari database aktif.

5. Keamanan (Security) Memberikan keamanan atas hak akses data.

6. Kebersamaan pemakaian (Sharability) Bersifat multiuser, sehingga memungkinkan untuk penggunaan data lebih dari satu orang.

\subsection{Diagram Input Proses Output}

Berikut ini adalah diagram Input Proses Output (IPO) yang memperjelas konsep solusi di atas:

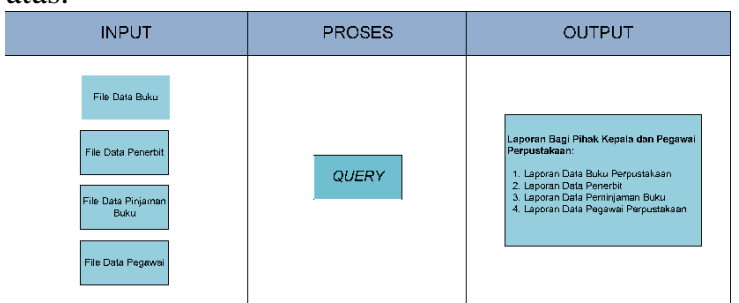

Gambar 1. Diagram IPO 


\section{Hasil dan Pengujian}

\subsection{Hasil}

Semua hasil rancangan yang telah dibuat dalam tahap perancangan akan diimplementasikan dengan bantuan Microsoft Access 2007, sehingga menghasilkan suatu sistem informasi manajemen perpustakaan (SIMPUS). Sistem informasi manajemen perpustakaan yang dihasilkan memiliki user interface(antarmuka pengguna) yang bersifat user friendly dan data-data di dalamnya dikelompokkan sesuai dengan sifatnya sehingga konsep Group Technology telah diterapkan di dalam sistem informasi manajemen perpustakaan yang dihasilkan. Adapun tampilan utama SIMPUS merupakan tampilan pertama kali masuk setelah memasukkan password pada perintah masukan password sebelum masuk SIMPUS.

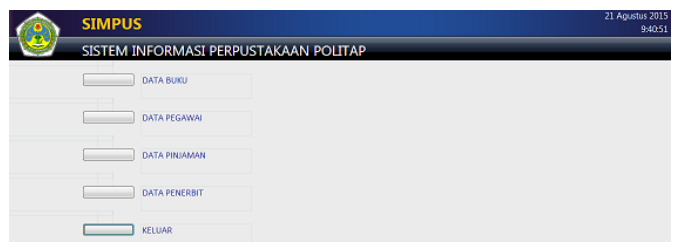

\section{Gambar 2. Tampilan Menu Utama SIMPUS}

\subsection{Pengujian dan Pembahasan}

Sistem informasi manajemen perpustakaan yang telah dihasilkan akan dilakukan tahapan pengujian. Pengujian tersebut dimaksudkan agar SIMPUS yang telah dihasilkan dapat dipastikan berjalan dengan baik, sehingga tidak terdapat lagi error/kesalahan yang terjadi di dalam SIMPUS tersebut.

Hasil dari pengujian SIMPUS dapat dilihat pada tabel berikut:

Tabel 1. Tabel Hasil Pengujian

\begin{tabular}{|c|c|c|c|}
\hline $\begin{array}{c}\text { Nama } \\
\text { Pengujian }\end{array}$ & $\begin{array}{c}\text { Bentuk } \\
\text { Pengujian }\end{array}$ & $\begin{array}{c}\text { Hasil yang } \\
\text { Diharapkan }\end{array}$ & $\begin{array}{c}\text { Hasil } \\
\text { Pengujian }\end{array}$ \\
\hline $\begin{array}{c}\text { Pengujian } \\
\text { Login }\end{array}$ & $\begin{array}{c}\text { Memasukkan } \\
\text { password }\end{array}$ & $\begin{array}{c}\text { Muncul } \\
\text { tampilan }\end{array}$ & Berhasil \\
\hline $\begin{array}{c}\text { Pengujian } \\
\text { masuk }\end{array}$ & $\begin{array}{c}\text { Klik data } \\
\text { peralatan }\end{array}$ & $\begin{array}{c}\text { Muncul } \\
\text { tampilan }\end{array}$ & Berhasil \\
\hline $\begin{array}{c}\text { Pengujian } \\
\text { masuk }\end{array}$ & $\begin{array}{c}\text { Klik data } \\
\text { pegawai }\end{array}$ & $\begin{array}{c}\text { Muncul } \\
\text { tampilan }\end{array}$ & Berhasil \\
\hline $\begin{array}{c}\text { Pengujian } \\
\text { masuk }\end{array}$ & $\begin{array}{c}\text { Klik data } \\
\text { pinjaman }\end{array}$ & $\begin{array}{c}\text { Muncul } \\
\text { tampilan }\end{array}$ & Berhasil \\
\hline $\begin{array}{c}\text { Pengujian } \\
\text { masuk }\end{array}$ & $\begin{array}{c}\text { Klik data } \\
\text { merk }\end{array}$ & $\begin{array}{c}\text { Muncul } \\
\text { tampilan }\end{array}$ & Berhasil \\
\hline
\end{tabular}

Setelah dilakukan pengujian, seluruh menu yang ada di dalam SIMPUS seperti yang terlihat pada tabel 1 di atas, semua menu di dalamnya dapat berfungsi dengan baik dan sesuai dengan rancangan yang telah dibuat pada tahap sebelumnya.

\section{Kesimpulan dan Saran}

\subsection{Kesimpulan}

Dari hasil pengujian dan analisis Sistem Informasi Manajemen Perpustakaan ini, maka dapat disimpulkan hal-hal sebagai berikut:

1. Sistem Informasi Manajemen Perpustakaan bermanfaat untuk memantau informasi dan data-data yang dimiliki oleh Perpustakaan Politeknik Negeri Ketapang berupa data buku yang masuk (baru) ataupun data buku yang keluar (ada atau dipinjam).

2. Sistem Informasi Manajemen Perpustakaan ini telah memenuhi standar keamanan, karena dilengkapi dengan password untuk masuk ke dalam menu utama, sehingga tidak semua orang dapat mengakses SIMPUS ini.

3. Sistem Informasi Manajemen Perpustakaan ini menggunakan prinsip paperless namun tidak menghilangkan etika simpan pinjam buku perpustakaan.

\subsection{Saran}

Beberapa saran yang dapat diberikan untuk penelitian selanjutnya sebagai berikut:

1. Sistem Informasi Manajemen Perpustakaan ini dapat dikembangkan lebih lanjut dengan sistem

2. Sehingga para peminjam buku perpustakaan dapat mencari informasi mengenai pinjaman buku yang dipinjam di mana saja berada online

3. Melakukan backup data pada tabel pinjaman, agar user tetap memiliki data history pinjaman, meski terjadi kerusakan pada sistem.

4. Menambah tabel "blacklist" yang berisikan peminjam barang perpustakaan yang tidak bertanggung jawab (mengembalikan selalu telat, pernah merusak fasilitas perpustakaan dan lain sebagainya yang bersifat merugikan.

\section{DAFTAR PUSTAKA}

Abdul Kadir \& Terra Ch. Triwahyuni. (2003). Pengenalan Teknologi Informasi. Andi Offset. Yogyakarta.

Andyono, Gebyar, (2007). Analisis Kebutuhan Sistem Informasi dan Desain Sistem Pariwisata untuk Kawasan Resort Hutan. Universitas Gajah Mada, Yogyakarta.

Billo, et al., (1988). Enhancing Group Technology Modeling with Database Abstractions. Arizona State University, Arizona.

Edhy, S., (1995). Sistem Pengolahan Basis Data Konsep dan Peranannya Dalam 
Informasi Manajemen, Edisi Pertama, Penerbit Andi, Yogyakarta.

Fathansyah, (2004). Buku Teks Komputer Sistem Basis Data. Penerbit Informatika, Bandung.

Hoffer, Jeffrey, A, et all. (2002). Modern Database management. New Jersey: Pearson Edecation, Inc.
McLeod, R., (1998). Management Information System. Prentice-Hall International, New Jersey. 